\title{
The effect of parenteral application of vitamin $A$, vitamin $E$, and $\beta$-carotene to pregnant cows on selected indices in their calves
}

\author{
Romana Kadek, Karolína Mikulková, Jaroslav Filípek, Josef Illek \\ University of Veterinary Sciences, Faculty of Veterinary Medicine, Large Animal Clinical Laboratory, \\ Brno, Czech Republic \\ Received December 25, 2020 \\ Accepted May 26, 2021
}

\begin{abstract}
The aim of the study was to determine the effect of parenteral application of vitamin preparations containing vitamins A, E, and $\beta$-carotene to pregnant cows (10-14 days before calving) on vitamin concentrations, haematological indices and the total antioxidant status (TAS) in their calves. Thirty cows were divided into 3 groups - control, the experimental group 1 (vitamins A, E), and experimental group 2 ( $\beta$-carotene). Blood sampling in calves was performed immediately after birth, $2 \mathrm{~h}$ after receiving colostrum, $24 \mathrm{~h}$ after birth and 5-7 days after birth. The calves received the first 4 doses of colostrum from their mothers. The highest concentration of vitamin E was observed 5-7 days after birth in group 1 compared to the control $(P<0.05)$ and group $2(P<0.01)$. The concentration of $\beta$-carotene was the highest in group $2(2$ and $24 \mathrm{~h}$ after receiving colostrum) compared to group $1(P<0.01)$. The TAS was the highest in group 1 compared to the control $(P<0.05, P<0.001)$ and group $2(P<0.01)$. A significant increase in haemoglobin $(P<0.01, P<0.05)$ and haematocrit $(P<0.05, P<0.01)$ was recorded in group 1 and group 2, respectively, compared to the control, as well as in the red blood cell count $(P<0.05)$ in group 2 compared to the control. The highest total protein was observed in the control group in all samplings. Parenteral application of vitamins to pregnant cows most likely had an effect on the concentrations of vitamins, TAS and haematological indices in their calves.
\end{abstract}

Cattle, total antioxidant status, haemoglobin, erythrocytes, colostrum

Maintaining optimal health in calves has a significant impact on their future health condition, production, and reproduction. A healthy and prosperous calf is a prerequisite for a healthy adult with high production as well as good reproductive results. The need to administer a sufficient amount of quality colostrum to ruminant neonates is already a wellresearched and indispensable fact. It is also well known that in ruminants only a negligible amount of fat-soluble vitamins as large molecules are transported through placenta from a cow to the fetus (Blum et al. 1997; Zanker et al. 2000).

Insufficiency of vitamins $\mathrm{A}, \mathrm{E}$, and $\beta$-carotene has negative consequences on the calves' health and viability (Kume and Toharmat 2001). High calf mortality in herds appears to be more common due to low levels of $\alpha$-tocopherol and $\beta$-carotene (Torsein et al. 2011). The concentration of these vitamins dramatically decreases in cows during the peripartum period (Illek et al. 2009; Píšt'ková et al. 2019).

Although the quality of colostral immunity is currently checked in standard farming practise by monitoring indices such as total protein (TP) and immunoglobulins (IgG), the concentrations of vitamins A, E and $\beta$-carotene in calves' serum often escape attention, which can have negative consequences on the calves' health.

As an antioxidant, vitamin E protects cells from oxidative damage and as an immunopotentiator, it provides additional immunity, also enhancing the calf's viability when fed to pregnant cows in the peripartum period (Panda and Kaur 2007). It has a protective effect on erythrocytes (RBC) against auto- and peroxidative haemolysis (Siddons and Mills 1981). In the study by Otomaru et al. (2015), oral supplementation 
of vitamin $\mathrm{E}$ had an effect on the population of leukocytes (WBC) in the peripheral blood of calves.

Studies on carotenoids and retinoids have been performed to determine their effect on the immune system in vivo and in vitro. Beta-carotene and all-trans retinoic acid (vitamin A metabolite) play an important role in the differentiation of immune-competent cells as well as in the proliferation of lymphocytes (Rühl 2007); moreover, vitamin A and $\beta$-carotene supplementation strengthens the immune system of newborns (Chew and Park 2004; Rühl 2007). Similarly to vitamin E, $\beta$-carotene is a powerful antioxidant, and in addition, it can function separately from provitamin A in cattle (Chew 1993). Also the effect of vitamin $\mathrm{A}$ on $\mathrm{RBC}$ and its association with anaemia has been described (Semba and Bloem 2002).

In the present study, two vitamin preparations containing vitamina $A, E$, and $\beta$-carotene were administered parenterally to Holstein cows 10-14 days before expected calving. After birth, the calves received the first 4 doses of colostrum from their own mothers. Our aim was to evaluate the level of vitamins $\mathrm{A}, \mathrm{E}$, and $\beta$-carotene, haematological indices, TP, IgG, albumin (Alb) and the total antioxidant status (TAS) of these calves from birth till 7 days of their life, as well as to find out whether this method of administering vitamins can improve these indices in neonatal calves and thus contribute to their better health and immunity.

\section{Materials and Methods}

Animals and administration of vitamins

The study was carried out from March 2019 to August 2019 following the local Research Ethics Committee approval, on the Holstein cattle dairy farm in Nový Jičín, Czech Republic.

Thirty pregnant Holstein cows in 1-3 lactations were selected for the experiment. Only clinically healthy cows with the average body condition score of 3-3.5 without any metabolic or infectious disease were selected for the experiment. The cows were housed on a deep straw mat with access to water ad libitum and fed a ration for dry cows.

The cows were divided into three groups: control; experimental group 1 with the administration of a vitamin formula containing vitamins A, E, and D; and experimental group 2 with the administration of $\beta$-carotene. The vitamin preparations were administered according to each group in the period of 10-14 days before the planned calving. Group 1 received $10 \mathrm{ml}$ of ADE - vit injection solution (Bioveta, Ivanovice/Hané, Czech Republic) intramuscularly. This vitamin preparation contains $100000 \mathrm{IU}$ retinoli propionas, $100000 \mathrm{IU}$ ergocalciferolum, and $30 \mathrm{mg}$ tocoferoli alfa acetas. Vitamin D was not taken into account or evaluated in this study. Group 2 received $20 \mathrm{ml}$ of carofertin $10 \mathrm{mg} / \mathrm{ml}$ (Betacarotenum $10.00 \mathrm{mg}$; Alvetra \& Werfft GmbH, Neufeld an der Leitha, Austria) subcutaneously.

The births of all cows in the experiment took place spontaneously. Prompt assistance was provided when a controlled thrust was required. The calf's umbilicus was treated with iodine solution first immediately after birth and the second time after transferring to the profilactorium.

Each calf received the first four doses of colostrum from its own mother. The colostrum of the cows was milked and used for the first (within $2 \mathrm{~h}$ after birth), the second (within $6 \mathrm{~h}$ after birth), the third and the fourth (next day) feeding of their own calves. The first dose of colostrum (31) was administered to the calves using an oesophageal tube according to the operating rules of the farm. The second (21), third (31), and fourth (3 1) doses of colostrum were fed using a bottle with a nipple. The composition of the milk replacer is given in Table 1. Clinical conditions of calves such as viability, rectal temperature, heart and respiratory rate, sucking reflex, possible occurence of diarrhoea, cough, nasal discharge, faecal consistency, and flexor contractures were monitored at each blood collection.

\section{Sampling and analysis}

The first blood sample was taken from the calves by jugular venipuncture after postnatal treatment before receiving the first dose of colostrum. The second and third blood samplings were carried out $2 \mathrm{~h}$ and $24 \mathrm{~h}$ after calving, respectively. The fourth blood sample was taken 5-7 days after birth during the period of conversion to the milk replacer. The blood samples were collected into Hemos sampling tubes (HEMOS H-02, GAMA Group, České Budějovice, Czech Republic) without anticoagulant for serum determination. The blood samples for haematology examination were collected into sampling tubes containing ethylenediaminetetraacetic acid (EDTA) anticoagulant.

After the sampling, serum was allowed to clot at room temperature, then separated after centrifugation at $3,000 \mathrm{~g}$ for $10 \mathrm{~min}$, and then stored at $-70{ }^{\circ} \mathrm{C}$ until the analysis. The following indicators were determined in the calf serum: vitamin A, vitamin E, $\beta$-carotene, IgG, TAS, TP, Alb. 
Determination of vitamins

The concentrations of vitamin A, E and $\beta$-carotene were determined using the High-Performance Liquid Chromatography (HPLC) system Ultimate 3000 (Dionex, Sunnyvale, USA) according to Sowell et al. (1994) with minor modifications. The blood samples for determination of vitamins were extracted (hexane), followed by evaporation and dissolution in the mobile phase (methanol).

Determination of $\mathrm{IgG}$

The determination of IgG was performed by photometric determination (Libra S6, Biochrom, Cambridge, United Kingdom) - turbidity test according to McEwan et al. (1970). Precipitation of serum immunoglobulins took place with a solution of zinc sulphate $\left(\mathrm{ZnSO}_{4}\right)$. The intension of turbidity is directly proportional to the IgG at a wavelength of $630 \mathrm{~nm}$.

Determination of TAS, TP, and Alb

The determination of TAS, TP, and Alb was performed using standardized kits supplied by Randox Laboratories Ltd, Crumlin, Antrim, United Kingdom (TAS) and BioVendor commercial kits, Brno, Czech Republic (TP and Alb) on an automatic Konelab 20XT biochemical analyzer (Thermo Fisher Scientific, Vantaa, Finland). The analyses were performed according to the manufacturer's instructions.

Determination of haematological indices

Blood anticoagulated with EDTA was analysed for WBC, RBC, haemoglobin (HGB), and haematocrit (HCT) by an automated veterinary haematology analyser BC-2800 (Mindray, Nanshan, Shenzhen, China). The samples for haematological examination were analysed immediately after blood collection.

Statistical analysis

The obtained results were tested for homogeneity of variances (Hartley-Cochran-Bartlett test) and normality of distribution (Shapiro-Wilk test). The data were analysed statistically by a one-way analysis of variance (ANOVA) followed by Fisher's LSD post hoc test. All results were expressed as mean value (x) \pm standard deviation (SD). A $P$ value $\leq 0.05$ was considered as significant.

\section{Results}

Concentrations of vitamins $\mathrm{A}$ and $\mathrm{E}$, and $\beta$-carotene for each group and time of sampling are shown in Figs 1-3.

Highly significantly increased vitamin A concentrations were observed in the control group compared to group $1(P<0.001)$ in serum taken 5-7 days after birth. Also Vitamin A in group 2 was also higher compared to group $1(P<0.01) 7$ days after birth.

A significant difference between groups was observed for serum vitamin E concentration in calves 5-7 days after birth. The highest serum vitamin E concentration in this period was found in the calves of group 1 compared to the control $(P<0.05)$ and group 2 $(P<0.01)$. The tendency to the highest concentration of vitamin $\mathrm{E}$ was observed in all samples of group 1 .

Table 1. Composition of the milk replacer.

\begin{tabular}{lc}
\hline Components & Amounts and units \\
Vitamin A & 25000 I.U. \\
Vitamin D3 & 10000 I.U. \\
Vitamin E & 500 I.U. \\
Protein & $26 \%$ \\
Fat & $16 \%$ \\
Fiber & $0 \%$ \\
Ash & $7 \%$ \\
Calcium & $0.90 \%$ \\
Natrium & $50 \%$ \\
Phosphorus & $0.70 \%$ \\
\hline
\end{tabular}

Significantly increased $(P<0.01) \beta$-carotene concentrations were observed between group 1 and group 2 in serum samples taken $2 \mathrm{~h}$ and $24 \mathrm{~h}$ after receiving colostrum. The tendency to the highest concentration of $\beta$-carotene was observed in all samples of group 2 .

Concentrations of serum $\mathrm{TP}, \mathrm{IgG}$, and $\mathrm{Alb}$ are shown in Table 2. The concentration of TP was significantly increased in the control in all samples compared to groups 1 and 2. Significantly increased concentration of $\mathrm{IgG}$ was observed in group 2 before receiving colostrum. The Alb concentration was significantly increased in group 2 compared to the control $(P<0.05)$ and group $1(P<0.01) 24 \mathrm{~h}$ after the first colostrum intake. Alb concentration in 


\section{The level of vitamin $A(\mu \mathrm{mol} / \mathrm{l})$ in all 4 samplings}

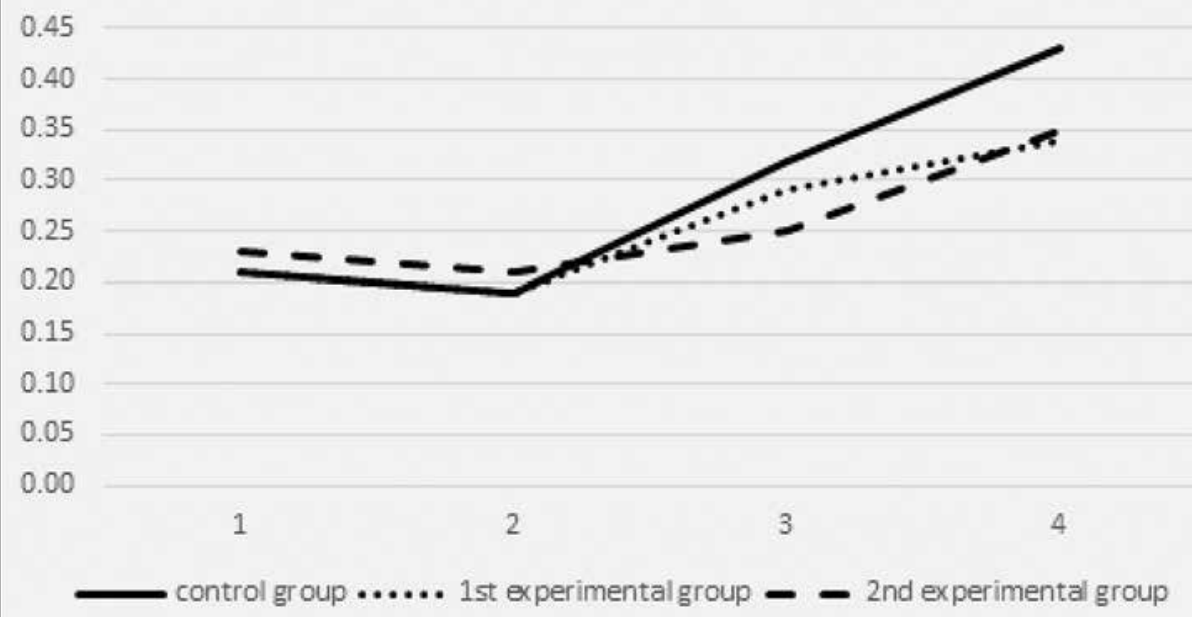

Fig 1. The concentration of vitamin A within groups during all four samplings

1 - first sampling, before receiving colostrum; 2 - second sampling, $2-3 \mathrm{~h}$ after receiving colostrum; 3 - third sampling, $24 \mathrm{~h}$ after receiving colostrum; 4 - fourth sampling, 5-7 days after birth

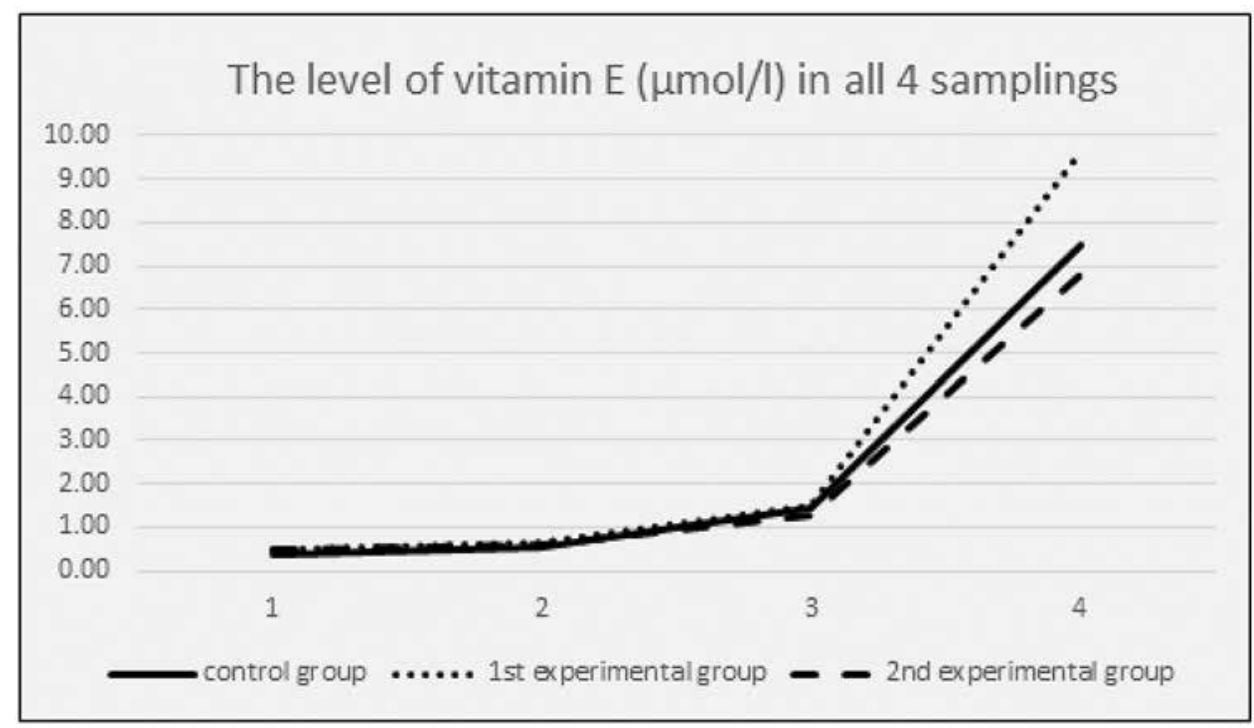

Fig. 2. The concentration of vitamin $\mathrm{E}$ within groups during all four samplings

1 - first sampling, before receiving colostrum; 2 - second sampling, 2-3 h after receiving colostrum; 3 - third sampling, $24 \mathrm{~h}$ after receiving colostrum; 4 - fourth sampling, 5-7 days after birth 


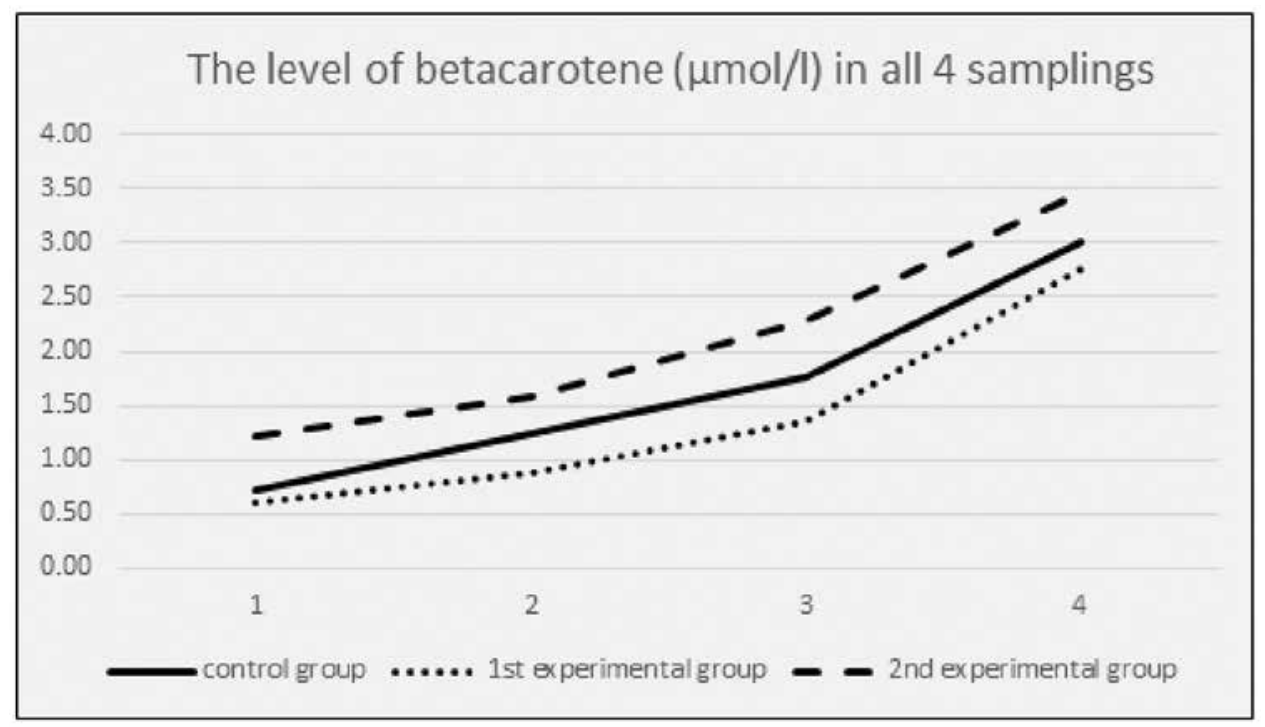

Fig. 3. The concentration of $\boldsymbol{\beta}$-carotene within groups during all four samplings

1 - first sampling, before receiving colostrum; 2 - second sampling, $2-3 \mathrm{~h}$ after receiving colostrum; 3 - third sampling, $24 \mathrm{~h}$ after receiving colostrum; 4 - fourth sampling, 5-7 days after birth

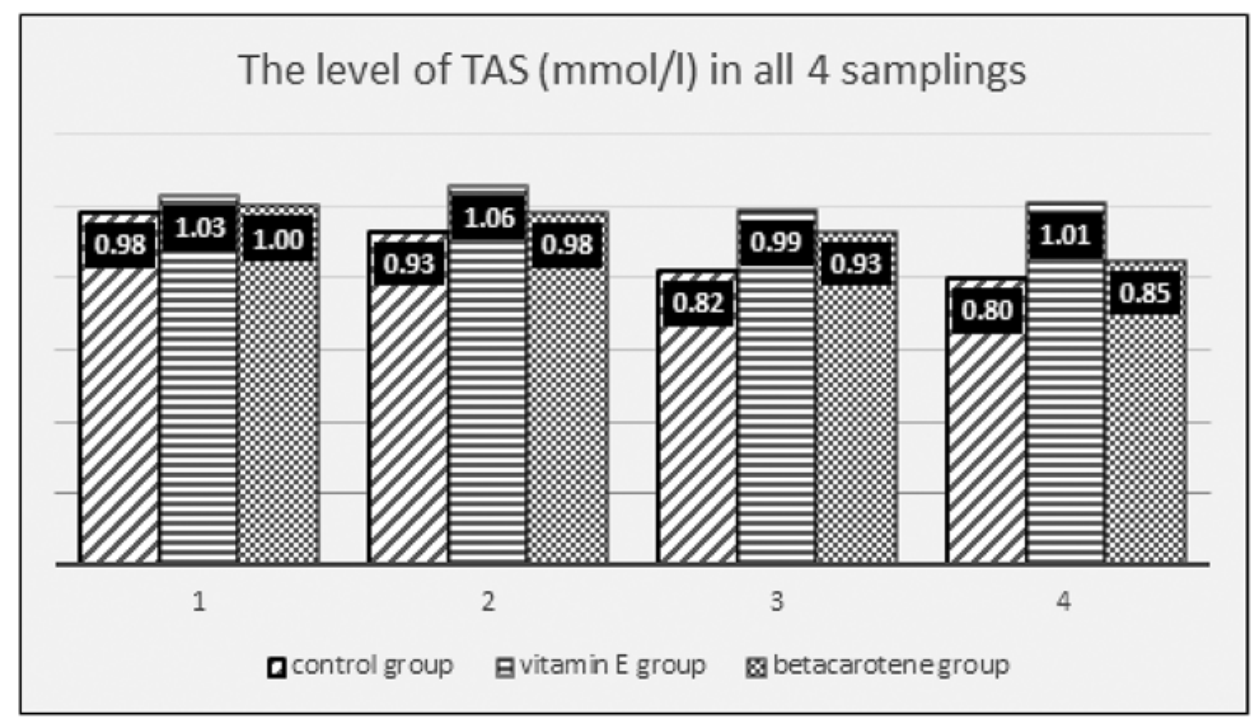

Fig. 4 The total antioxidation status (TAS) within groups in all four samplings

1 - first sampling, before receiving colostrum; 2 - second sampling, $2-3 \mathrm{~h}$ after receiving colostrum; 3 - third sampling, $24 \mathrm{~h}$ after receiving colostrum; 4 - fourth sampling, 5-7 days after birth 


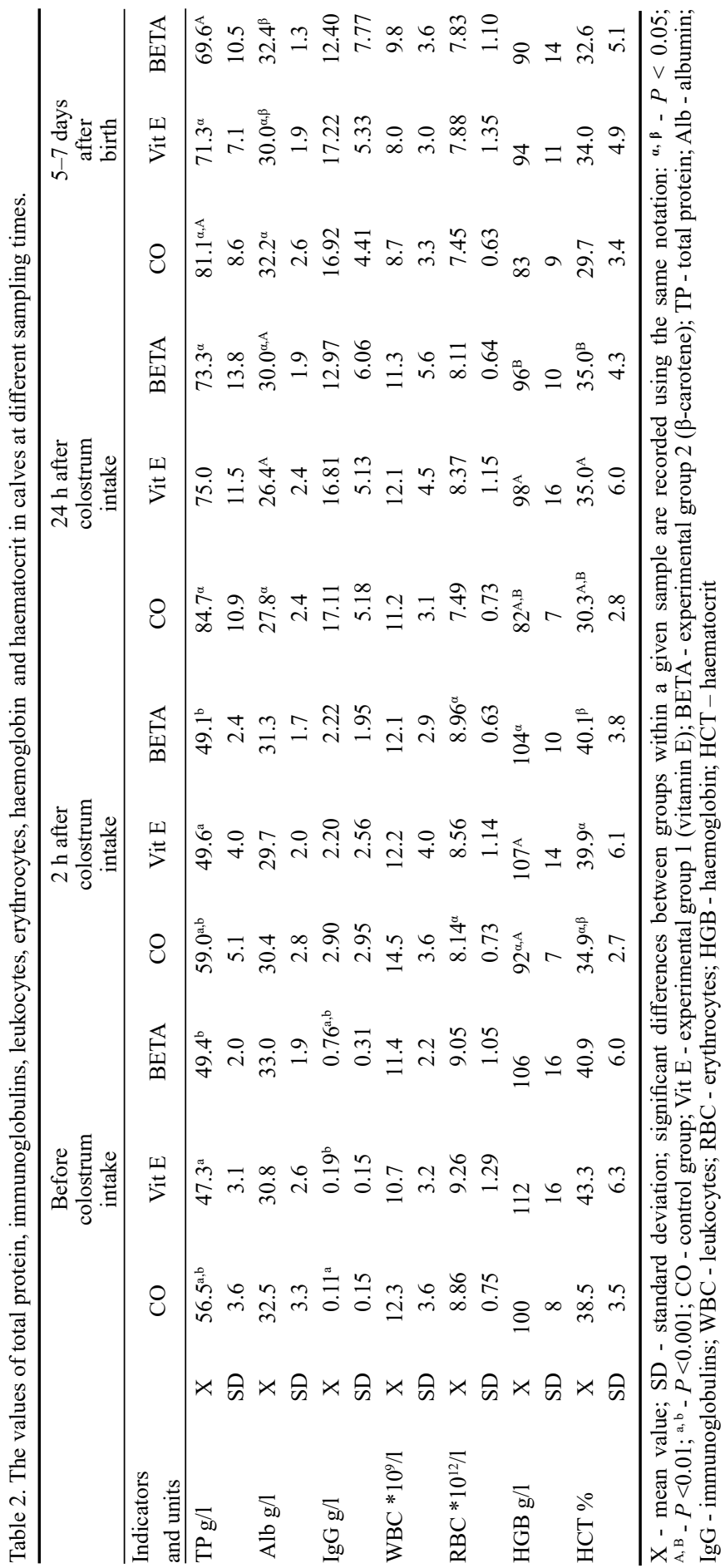

calves of group 2 was also significantly increased 5-7 days after birth compared to group $1(P<0.05)$. The control group also showed a significantly higher concentration of Alb $(P<0.05)$ compared to group 1 in this sampling.

The TAS (Fig. 4) was significantly increased $(P<0.05) 2 \mathrm{~h}$ after receiving colostrum in group 1 compared to the control and also $24 \mathrm{~h}$ after receiving colostrum in group 1 compared to the control $(P<0.01)$ and group $2(P<0.05)$. Group 1 also had the highest TAS in the last sampling (5-7 days after birth) compared to the control $(P<0.001)$ and group $2(P<0.01)$.

No significant differences were found between the groups of calves within individual WBC samples (Table 2). On the other hand, the HGB concentrations recorded in group 1 and group 2 were significantly increased $(P<0.01$, $P<0.05$, respectively) compared to the control $2 \mathrm{~h}$ after receiving colostrum and also within $24 \mathrm{~h}$ after receiving colostrum $(P<0.01)$.

A significantly increased HCT concentration (Table 2) was also observed in group 1 $(P<0.05)$ and group 2 $(P<0.05)$ compared to the control $2 \mathrm{~h}$ after receiving colostrum and also within $24 \mathrm{~h}$ after receiving colostrum $(P<0.01)$.

A significantly 
increased $(P<0.05)$ RBC (Table 2) was also found in the calves of group 2 compared to the control $2 \mathrm{~h}$ after receiving colostrum.

\section{Discussion}

The calves in our experiment had the highest concentrations of vitamins in the fourth sampling (5-7 days after birth). This also agrees with the results of other authors, where the concentration of vitamins in calves significantly increased in the period of 3-7 and more days after birth (Zanker et al. 2000; Krueger et al. 2014; Torsein et al. 2018; Kadek et al. 2019). The experimental group 1 of calves whose mothers received a parenteral injection containing vitamins $\mathrm{A}, \mathrm{E}$, and $\mathrm{D}$ showed higher concentrations of vitamin $\mathrm{E}$ compared to the other groups. Similarly, the highest levels of $\beta$-carotene in all samplings were shown in the experimental group 2 of calves whose mothers received parenteral $\beta$-carotene. The $\beta$-carotene concentrations have been proven to increase rapidly in calves following the colostrum intake (Blum et al. 1997). On the other hand, the vitamin A concentrations were the highest in the control group at 5-7 days of age. In the study by Puvogel et al. (2008) the calves that were fed colostrum from cows orally supplemented with a higher amount of vitamin $\mathrm{A}$ in the late gestation period had increased plasma retinol concentrations from 14 to 30 days after birth compared to the control group. However, there was no significant difference in the level of vitamin A up to 5 days after birth.

All calves from the control group had significantly increased TP compared to the experimental groups. Although all calves in our study had been properly fed with colostrum, there are several factors that may have affected the level of TP and thus IgG in calf serum (Donovan et al. 1986; Villarroel et al. 2013). We considered that in our work the TP, $\mathrm{Alb}$, and $\mathrm{IgG}$ in calf serum were not influenced by vitamin administrations to pregnant cows. On the other hand, in the work by Krueger et al. (2014) newborned Holstein bulls injected with a vitamin preparation containg vitamins E, A, and D had increased plasma IgG1 concentrations. Beta-carotene supplemented orally did not significantly influence antibody titres after vaccination in Japanese black calves (Otomaru et al. 2018). The IgG concentration of group 2 was the highest before colostrum intake compared to the other groups in this sampling. We believe that this could be due to a viral pathogen. However, the cows selected for the experiment were clinically healthy. The IgG concentration of group 2 was non-significantly lower in the sampling $24 \mathrm{~h}$ after colostrum intake and 5-7 days after birth compared to the other groups. In our opinion, this may have been influenced by the rate of $\mathrm{IgG}$ resorption in the intestine. There is also greater variability of values in these results.

The TAS is an indicator of antioxidant defense capacity and all antioxidant mechanisms. In our results, group 1 showed the highest TAS in all samplings. The mothers of this group of calves received a vitamin formula which contained vitamins E, A and D. Vitamin E is a potent antioxidant that protects cells from oxidative damage. In the work by Otomaru et al. (2018), calves supplemented orally with $20 \mathrm{mg}$ of $\beta$-carotene showed reduced oxidative stress and increased oxidative capacity. Pišt'ková et al. (2019) and Mikulková et al. (2020) reported the lowest TAS in cows 2-3 days after calving, when the lowest levels of vitamin E, vitamin A and $\beta$-carotene were also found. In calves of the Aberdeen Angus breed, the parenteral administration of subcutaneous vitamins and minerals (including vitamins A and E) with antioxidant effects prevented a decrease in TAS (Mattioli et al. 2020).

There were no significant changes in WBC in the calves in our study. However, the response of bovine $\mathrm{WBC}$ to vitamins depends on the age of the calf (Lee and Roth 1992), the degree of supplementation (Eicher-Pruiett et al. 1992), and the function under observation (Hogan et al. 1992). A study performed in Japanese black calves found 
that oral supplementation of vitamin $\mathrm{E}$ at the dose of $300 \mathrm{IU} /$ day affected the number of certain WBC types in the peripheral blood of calves (Otomaru et al. 2015). Vitamins can also improve the WBC functions, such as bactericidal activity, phagocytosis, and the chemotactic index (Eicher et al. 1994).

All calves from both experimental groups whose mothers were injected with vitamin preparations before calving had a tendency to increased haematological indices (RBC, $\mathrm{HGB}$, and HCT) in all samples. A significant increase in RBC was observed in group 2 ( $\beta$-carotene) $2 \mathrm{~h}$ after birth. Another significant increase was observed in HGB and HCT in both experimental groups $2 \mathrm{~h}$ after calving and $24 \mathrm{~h}$ after calving.

Siddons and Mills (1981) revealed that vitamin E is essential for stabilizing the RBC in calves. The calves with low vitamin $\mathrm{E}$ intake showed increased auto- and peroxidative haemolysis of RBC. On the other hand, in this work, dietary supplementation of vitamin E did not affect haematological indices in calves. Similarly, in the study by Stevenson and Jones (1989), the sensitivity of sheep RBC was affected by and directly related to the concentration of vitamin E.

The likely mechanism of vitamin A in its effect on haematological indices and anaemia is through enhancing the growth and differentiation of erythrocyte progenitor cells, strengthening the immune system during infection, and mobilizing iron from tissue sources (Semba and Bloem 2002). In the study by Moosavian et al. (2010), the injection of vitamin A (alone or in combination with $\mathrm{Fe}$ ) caused higher $\mathrm{RBC}$ in neonatal calves. However, the differences were not significant. In another research, neonatal calves supplemented with vitamin A in diet had increased RBC. However, a significant increase was found for HGB only (Muri et al. 2005).

Beta-carotene has been shown to be an effective antioxidant for the protection of RBC in the field of human medicine (Revin et al. 2019). In addition to being a potent antioxidant, $\beta$-carotene has a very specific antioxidant effect in RBC phospholipid bilayers compared to plasma and other tissues (Nakagawa et al. 1996).

In conclusion, calves whose mothers received vitamin injections 14 days before birth had the highest concentrations of vitamins $\mathrm{E}$ and $\beta$-carotene in all samples. Thus, injecting vitamins to pregnant cows before parturition is likely to affect the vitamin $\mathrm{E}$ and $\beta$-carotene levels in the calf serum. Parenteral administration of vitamins to cows did not affect the WBC in the blood of their calves, but probably affected the RBC, HGB, and HCT. Group 1 of calves showed the highest TAS. The control group of calves showed the highest TP. The administration of vitamins to cows did not affect the level of TP, IgG, and Alb in the serum of calves. Further research is needed on the effect of the application of vitamin preparations to cows before parturition in relation to the levels of individual indices, immunity and antioxidant status in the blood of their calves.

\section{Acknowledgement}

This study was supported by the grant IGA VFU Brno 106/2019/FVL, University of Veterinary and Pharmaceutical Sciences Brno, Czech Republic.

\section{References}

Blum JW, Hadorn U, Sallmann HP, Schuep W 1997: Delaying colostrum intake by one day impairs plasma lipid, essential fatty acid, carotene, retinol and $\alpha$-tocopherol status in neonatal calves. J Nutr 127: 2024-2029

Chew BP 1993: Role of carotenoids in the immune response. J Dairy Sci 76: 2804-2811

Chew BP, Park JS 2004: Carotenoid action on the immune response. J Nutr 134: 257S-261S

Donovan GA, Badinga L, Collier RJ, Wilcox CJ, Braun RK 1986: Factors influencing passive transfer in dairy calves. J Dairy Sci 69: 754-759

Eicher SD, Morrill JL, Blecha, F, 1994: Vitamin concentration and function of leukocytes from dairy calves supplemented with vitamin A, vitamin E and $\beta$-carotene in vitro. J Dairy Sci 77: 560-565

Eicher - Pruiett SD, Morrill JL, Blecha F, Higgins JJ, Anderson NV, Reddy PG 1992: Neutrophil and lymphocyte response to supplementation with vitamins C and E in young calves. J Dairy Sci 75: 1635-1642 
Hogan JS, Weiss WP, Todhunter DA, Smith KL, Schoenberger PS 1992: Bovine neuthrophil responses to parenteral vitamin E. J Dairy Sci 75: 399-405

Illek J, Kumprechtova D, Matejíček M, Vlček M 2009: Metabolic profile in high-producing dairy cows in different phases of the calving-to-calving interval. Folia Vet 1: 7

Kadek R, Tejnil I, Mikulková K, Illek J, Kumprechtová D 2019: Development of serum vitamin E and beta-carotene levels in heifer calves during the first 8 weeks of live. The Animal Biology 21: 106

Krueger LA, Beitz DC, Onda K, Osman M, O’Neil MR, Lei S, Wattoo FH, Stuart RL, Tyler HD, Nonnecke B 2014: Effects of D-alpha tocopherol and dietary energy on growth and health of preruminant dairy calves. J Dairy Sci 97: 3715-3727

Kume S, Toharmat T, 2001: Effect of colostral beta-carotene and vitamin A on vitamin and health status of newborn calves. Livest Prod Sci 68: 61-65

Lee CC, Roth JA 1992: Differences in neutrophil function in young and mature cattle and their response to IFN- $\gamma$. Comp Haematol Int 2: 140-147

Mattioli GA, Rosa DE, Turic E, Picco SJ, Raggio SJ, Minervino AHH, Fazzio LE 2020: Effects of parenteral supplementation with minerals and vitamins on oxidative stress and humoral immune response of weaning calves. Animals 10: 1298

McEwan AD, Fisher EW, Selman IE, Penhale WJ 1970: A turbidity test for the estimation of immune globulin levels in neonatal calf serum. Clin Chim Acta 27: 155-163

Mikulková K, Kadek R., Filípek, J, Illek, J 2020: Evaluation of oxidant / antioxidant status, metabolic profile and milk production in cows with metritis. Ir Vet J 73: 8

Moosavian HR, Mohri M, Seifi HA 2010: Effects of parenteral over-supplementation of vitamin A and iron on hematology, iron biochemistry, weight gain and health of neonatal dairy calves. Food Chem Toxicol 48: 1316-1320

Muri C, Schottstedt T, Hammon HM, Meyer E, Blum JW 2005: Hematological, metabolic and endocrine effect of feeding vitamin A and lactoferrin in neonatal calves. J Dairy Sci 88: 1062-1077

Nakagawa K, Fujimoto K, Miyazawa T 1996: Beta-carotene as a high-potency antioxidant to prevent the formation of phospholipid hydroperoxides in red blood cells of mice. Biochim Biophys Acta 1299: 110-116

Otomaru K, Saito S, Endo K, Kohiruimaki M, Ohtsuka H 2015: Effect of supplemental vitamin E on the peripheral blood leukocyte population in Japanese black calves. J Vet Med Sci 77: 985-988

Otomaru K, Ogawa R, Oishi Sh, IwamotoY, Hong H, Nahai K, Hyakutake K, Kubota Ch, Kaneshige T 2018 : Effect of beta-carotene supplementation on the serum oxidative stress biomarker and antibody titer against live bovine respiratory syncytial virus vaccination in Japanese black calves. Vet Sci 5: 102

Panda N, Kaur H 2007: Feeding synthetic vitamin E or milk from vitamin E supplemented Murrah buffaloes on growth, immunity and mineral status of calves. Anim Nutr Feed Techn 7: 1-10

Píšt'ková K, Illek J, Kadek R 2019: Determination of antioxidant indices in dairy cows during the periparturient period. Acta Vet Brno 88: 3-9

Puvogel G, Baumrucker C, Blum JW 2008: Plasma vitamin A status in calves fed colostrum from cows that were fed vitamin A during late pregnancy. J Anim Physiol Anim Nutr 92: 614-620

Revin VV, Gromova NV, Revina ES, Samonova AY, Tychkov AY, Bochkareva SS, Moskovkin AA, Kuzmenko TP 2019: The inflence of oxidative stress and natural antioxidants on morphopmetric parameters of red blood cells, the hemoglobin oxygen binding capacity, and the aktivity of antioxidant enzymes. Biomed Res Int 2019: 1-12

Rühl R 2007: Effects of dietary retinoids and carotenoids on immune development. Proc Nutr Soc 66: 458-469

Semba RD, Bloem MW 2002: The anemia of vitamin A deficiency: epidemiology and pathogenesis. Eur J Clin Nutr 56: 271-281

Siddons RC, Mills CF 1981: Glutathione peroxidase activity and erythrocyte stability in calves differing in selenium and vitamin E status. Br J Nutr 46: 345-355

Sowell AL, Huff DL, Yeager PR, Caudill SP, Gunter EW 1994: Retinol, alpha-tocopherol, lutein/zeaxanthin, beta-cryptoxanthin, lycopene, alpha-carotene, trans-beta-carotene, and four retinyl esters in serum determined simultaneously by reversed-phase HPLC with multiwavelength detection. Clin Chim Act 27: 411-416

Stevenson LM, Jones DG 1989: Relationships between vitamin E status and erythrocyte stability in sheep. J Comp Pathol 100: 359-368

Torsein M, Lindberg A, Sandgren CH, Waller KP, Törnquist M, Svensson C 2011: Risk factors for calf mortality in large Swedish dairy herds. Prev Vet Med 99: 136-147

Torsein M, Lindberg A, Svensson C, Jensen SK, Berg C, Waller KP 2018: $\alpha$-tocopherol and $\beta$-carotene concentrations in feed, colostrum, cow and calf serum in Swedish dairy herds with high or low calf mortality. Acta Vet Scand 60: 7

Villarroel A, Miller T, Johnson ED, Noyes KR, Ward JK 2013: Factors affecting serum total protein and immunoglobulin $\mathrm{G}$ concentration in replacement dairy calves. Adv Dairy Res 1: 106

Zanker IA, Hammon HM, Blum JW 2000: Beta-carotene, retinol and alpha-tocopherol status in calves fed the first colostrum at 0-2, 6-7, 12-13 or 24-25 hours after birth. Int J Vitam Nutr Res 70: $305-310$ 